\title{
The geography of maritime transport
}

\author{
Draft version of the chapter published in Vickerman R. (2021) International Encyclopedia of \\ Transportation, Elsevier, pp. 517-534.
}

César DUCRUET \& Justin BERLI

Centre National de la Recherche Scientifique (CNRS)

\begin{abstract}
This article reviews the multiple approaches to the spatial dimension of maritime transport. It covers a wide range of perspectives, from flow mapping, network analysis, actors' strategies, and local socio-economic determinants. It differs from classic descriptions of main routes, port traffic, and the evolution of the shipping industry by questioning what is the geography of maritime transport, what are its wider foci, its data and cartographic challenges, and its (inter)disciplinary character. While human geography pioneering the study and mapping of maritime transport in the 1940s, other disciplines such as economics, physics, engineering, management, and operations research took the lead up to nowadays. Far from pretending to be exhaustive, this article proposes an overview about whether "space" and "geography" kept their importance throughout the academic literature and beyond. It also puts great emphasis on the emergent visualisations of maritime flows in the last decade or so at the global and regional scales.
\end{abstract}

Keywords: cartography; data visualisation; flows; maritime transport; ports; shipping; spatial network

\section{Introduction}

Dealing with the geography of maritime transport has two directions of which only one can be chosen in this article: (a) doing a geography of maritime transport or (b) analysing the geography of maritime transport itself. Far from proposing an exhaustive review and comprehensive history like in a bibliometric study, we propose in this article to ask one central question: what makes maritime geography different from - or linked with - maritime / transport studies and geography / spatial sciences in general? Although such a question seems to point to a very specialised research arena, it has a wide range of possible answers. We thus selected two major issues that concern many other (if not all) arenas: a) data visualisation and spatial shift as well as b) network science and complex systems. Such an angle of attach has two merits. 
First, it avoids repeating the usual contents of maritime textbooks and official reports, where the evolution of technology, cost, and traffic is already well covered, and of dedicated geography handbooks showing major shipping routes, the ranking of world's top ports, and other features such as traffic distribution by fleet, continent, flag, etc. The majority of maritime geography long remained a descriptive collection of information constantly updated but with no ambition to connect other domains. Despite its pioneering role in mapping world shipping routes based on real data, maritime geography soon became closer to maritime economics and management with a growing emphasis on actors and their strategies, cf. the behavioural turn. But the spatial turn converged with a growing interest for the sea from other disciplines, so that numerous visualisations of maritime transport emerged in the past decade or so. In recent years, several international and/or non-governmental organizations produced huge reports about maritime transport using cartography, such as the United Nations mapping piracy acts since the mid-1990s (UNITAR) and calculating a Liner Shipping Connectivity Index (UNCTAD), the OECD measuring the competitiveness and visualizing the maritime forelands of global port cities, the World Bank displaying the connectivity, efficiency and economic development of Mediterranean maritime networks, and the European Commission Joint Research Center analyzing vessel position data for practical purposes and calculating a composite index of global urban accessibility including vessel flows (see a recent review in Ducruet, 2017). After presenting a critical review of existing visualizations of maritime transport, we propose a new methodology based on the new software Geoseastems.

Second, it is interesting to compare how maritime geography had been adopting dedicated analytical tools such as network analysis, from the early times up to nowadays. Is maritime transport a specific network? What is the influence of its spatial nature on its structure, morphology and topology? In this approach, the network concept will be extended to other dimensions such as firms networks in the maritime sector as well. This approach thus places the geography of maritime transport, should it be performed by geographers or not, at the centre of multiple arenas such as corporate studies, urban studies, network studies. To reach such an objective, recurrent topics such as port-city relationships, technological evolutions, traffic distribution, hinterland connectivity, port governance and supply chain integration will be inevitably dealt with, to name but a few. Case studies as well as general models are selected to further illustrate what is the geography of maritime transport.

\section{Mapping maritime transport}

\subsection{The evolution of classic maritime cartography}

It is a fact that only a dozen maps of world shipping flows have been produced until the years 2000s (Ducruet, 2015). Historically, maritime maps serve overseas explorations and are strongly impregnated by human imagination on sea monsters and mysterious places. In the nineteenth and early twentieth centuries, such maps gained in precision, indicating major and minor sea lanes, and sometimes the services of specific carriers, notwithstanding information on natural conditions. The emergence of flowmaps only occurred in the 1940s from French and U.S. geographers representing global maritime flows based on historical archives and customs data, employing, at the time, state-of-art technique of flow visualisation. 
In the mid-1970s, U.S. authorities provided a more systematic cartography of shipping flow density based on a world square grid. But filling cells with the number of vessel trips was not the most efficiency method compared with nowadays tools. Another exception is a PhD thesis from Le Havre University mapping the main interport container flows in the early 1990s. All other maps before the 2000s remained broadly estimated drawings of major maritime routes, published in related textbooks, but not based on actual data. Exceptions are traffic maps showing maritime trade volume per continent and region but not between them. Old data such as ship logs was used to produce similar maps but with a very different purpose: the reconstitution of past weather conditions across the globe (the CLIWOC project). Text-based sources and archeological records helped to reconstitute Roman and Greek routes of the Antiquity, while local port registers allowed to map $18^{\text {th }}$ century French trading routes (the Navigocorpus project), Venetian trade (1283-1453), slave voyages from Africa to the Americas (1514-1868), and an animation of British Royal Navy ship movements (1913-1925) using CartoDB. Other known sources on past maritime transport remain to be systematically exploited, such as the Suez Canal archives (1865-today), the Sound Toll Registers (1497-1857), and the Dutch East Indian Trading Corporation with 25 million ship records (1595-1795).

The discovery of Lloyd's List publications on global and daily vessel movements, covering approximately $80 \%$ of the world fleet and published since 1880 (1696 for the British fleet only) opened the path to plenty of previously unthinkable analyses, long-term and at the global scale. For instance, mapping the global maritime network at the continent level between 1890 and 2010 clearly confirmed the shift from Atlantic to Pacific, with the drawback of using vessel calls instead of vessel tonnage in recent years as ships grew in size and rationalized their services.

[Figure 1 about here]

About maritime transport as a firm or alliance, mainly French and Canadian geographers offered, from the mid-2000s onwards, maps of individual ocean carriers. Such a shift to more managerial aspects was motivated by the growing bargaining power of large companies over the entire supply chain including port and terminal operations as well as logistics. Data was usually obtained directly from websites or from yearbooks such as Containerisation International, detailed at a given point in time the scheduled services of each company. One of the first maps of the kind showed the service geography of Evergreen and COSCON in 1990 and 2000 with the main ports of call. Another study compared the global network of the largest shipping lines in 2002 based on no less than 601 services and 440 ports, but the maps were aggregated by continent. This helped to categorize firms and better understand their mainstream or niche strategies according to their geographic coverage and their nationality. Later on, parent studies followed, such about COSCON in 1990 and 2000, mapping its services related with China, to discuss competition and integration trends, and about the historical development of CMA-CGM and Maersk, questioning the respective roles of public and private forces conducting to routing choices, with a growing emphasis on market power and efficiency.

Finally, some types of studies looked at vertical integration, cooperation, and inter-firm agreements while others looked at maritime firms through the localisation of their headquarters and establishments, the local determinants of maritime advanced producer 
services (APS; e.g. finance, brokerage, insurance), should it be globally or at the intra-city level, also questioning their co-location with other APS or with commodity traders as well as their concentration in global cities. The modal specialization of cities was measured in Europe based on the portfolio of about 8,000 transport companies (Kompass database), discussing the varying importance of vertical integration and the strong national influence. Such studies looked more at the sectoral disaggregation rather than individual companies.

Other disaggregated works relevant to the geography of maritime transport also include the analysis of ship-to-ship interactions, should it be for military purposes (cf. tactical and telecommunication networks) or understanding a particular type of transfer of goods, people, or information as specific points in the sea, considering the ship "as a vehicle for knowing and understanding colonialism, commerce, trade and conflict; embodied and resistant performances, and residual materiality, demonstrating the place of the ship in geography". Certain geographers got even closer when interviewing captains and mariners to map their mental representation of the ocean, having in common with the former that maritime issues are peripheral in geography.

\subsection{The digital era}

Tremendous progress has been made since the early 2000s in the visualization of maritime transport. Numerous online tools serving the calculation of inter-port shipping distances, (e.g. Sea-distances, Searates), replacing the tedious port-to-port printed matrices. Other tools were designed to measuring intermodal shipping costs as well as the environmental, energy, and economic impact of freight transportation (e.g. GIFT model). Radar and satellite data had been the common material to be used for a wide variety of analyses and visualizations about ship emissions, environmental impacts of shipping, accidentology, navigability, security, vessel trajectories, and coastal management. The latter works remained somewhat separated from the ones presented in the previous section (social sciences), being more on the side of traffic engineering and operations research. Yet, this digital data could not go back prior the mid2000s, but gained in popularity with the emergence of numerous online resources of which the now famous marinetraffic.com providing the real time position of vessels, freely accessible.

Numerous maps using such real-time data were thus proposed, for the sake of obtaining a more precise vision of corridors by type of ship for instance (cf. cargo and tanker ships by ShipMix), a multilayered cartography of the Anthropocene (Globaïa), global heatmaps of ship densities (Marinetraffic and ExactEarth). Dynamic visualizations have also been proposed by FleetMon Satellite AIS and FleetMon Explorer, of which the Shipmap project looking at environmental impacts. Other explored issues include the analysis of ships' traces across oceans using Advanced Very High Resolution Radiometer (AVHRR) data from space, noise data from waves and currents of which anthropogenic (e.g. oceannoisemap.com) using for instance NOOA AIS data. The rise of online mapping solutions also includes the European Atlas of the Seas (European Commission), route-planning algorithms to model maritime paths, the upcoming Google Oceans application, and the OpenSeaMap project with complementary information on shipping lanes. 
Despite the mentioned advances, there was little if no possibility to map past maritime flows and thus to understand the long-term evolution of maritime transport. Figure 2 provides a recent example based on 2008 data of a flowmap and heatmap based on the same information. Each map shows a different dimension; the heatmap is somewhat biased by extreme values (port traffic) in East Asia while the flowmap is more precise in terms of global coverage and the distribution of routes, with lesser concentration. Such visualizations were made possible using a virtual maritime grid based on distance and cost of supporting links, after the world map had been divided into squares through eight iterations and their centroids linked with the impossibility to cross land surfaces.

[Figure 2 about here]

\section{Maritime transport as a (spatial) network}

The application of graph theory to maritime transport started in 1968, in a Canadian PhD thesis about Vancouver (Robinson, 1968), but had only a handful of followers until the late 1990 s and early 2000s in isolated theses and articles not even mentioning each other. A rapid count using Google Scholar revealed two facts: the very low number of works mentioning explicitly "maritime network" in French and English languages (i.e. less than $1 \%$ of all transport network studies) and the majority of such works using the concept of network in its common sense but without engaging in graph theory and the emerging network science. The main value of appying graph theory to maritime transport had been to provide local or global centrality and connectivity indicators, thereby creating more links with other modes and domains as well as complementing the usual description of tonnage. In this section, we discuss the merits and demerits of such a conceptual and methodological adoption through two main themes: regionalization and globalization; cities and regional development.

\subsection{From regional to global maritime networks}

\subsubsection{The maritime region as a framework}

Choosing a specific part of the world to study connections between ports made the study of maritime transport more geographic. Several studies of the kind emerged in the mid-2000s, about arbitrarily defined regions. This led to the questioning of comparability across regions and of the concept of "maritime region", often badly defined and corresponding to various realities such as façade, range, seaboard, basin, port system, etc. (Lewis and Wigen, 1999). The regional scale is also a way to discuss wider issues of which regional integration, transnational and cross-border studies, and the importance of proximity in the pattern of flows. Yet, such studies oscillate between understanding the network (actors), the region (territories), or both. A study of port geography papers ( $\mathrm{Ng}$ et al., 2014) concluded that among them, $48 \%$ focus on one single port, $32 \%$ on a single country, $14 \%$ on a transnational area, and $6 \%$ on the world. The national scale has been relevant for countries made of numerous islands, as seen with analyses of the Finnish, Indonesian, and Greek maritime networks, mainly from a passenger and regional planning perspective. 
Transnational studies mainly focused on container shipping, with many works on the Caribbean and Mediterranean basins, due to their situation as crossroads and the proximity to Panama and Suez canals, respectively. Network analysis was useful to compare the connectivity of intra- and extra-regional linkages, the role of main shipping lines versus alliances, and the emergence of hub ports. More recent studies explicitly questioned the integration level of specific systems, such as the North European port range from Le Havre to Hamburg, southern Africa, the Canary Islands, the East-West circumterrestrial corridor, and increasingly, the "new" Maritime Silk Road deployed by China through its vision "One Belt, One Road" (OBOR). Comparative studies also emerged, also including North Europe and East Asia, but mainly for the sake of further understanding transport actors, with little citations about regional studies.

The main outcome had been to observe variations in the level of regional network centralization around hubs, from homogenous to polarized or polycentric maritime regions; some of them being more or less under the influence of alliances, hubs, and related dynamics such as the rationalization of services. Another result was that the multiplication of nodes and links could mean both regional integration and transhipment hub centralization, depending on the context. Nevertheless, such regional studies often faced the difficulty of disentangling flows of various scale (e.g. short-sea shipping, trunk lines, and feedering) as well as territorial versus supply chain effects.

Another outcome had been to reveal the influence of political borders and other "barrier effects" on the changing distribution of regional maritime networks. First came a series of works on North Korea, revealing its shrinking maritime foreland due to internal and external crisis following the end of the USSR and socialist block; the multiplication of inter-Korean shipping linkages following the 2000 presidential summit and the 2004 maritime agreement, and even the concentration of most North Korea's traffic between the main ports of the respective capital cities, Nampo and Incheon, before North Korea's connections became, in the late 2000s, dominantly Chinese (Figure 3). Similar maps were proposed to study the interplay between border effects and shipping patterns in Maghreb, Northwest Africa, South Asia, and the Soviet Union, at times of crisis and independence, showing important shifts overtime. In central Maghreb, ports of the three countries (i.e. Morocco, Algeria, and Tunisia) remained disconnected in the mid-1990s. Ten years later, Algiers somewhat increased its dominance, albeit mainly domestic, until the opening of the new hub Tangier-Med (2008) attracted all the regions' main flows for transhipment, competing with the other external hubs of Algeciras and Marsaxlokk. At the contrary, the analysis of the Northeast Asian liner shipping network since the mid-1990s questioned the rise of Shanghai as Asia's new hub. The application of single linkage analysis demonstrated that South Korea, and in particular Busan port, remained dominant in the region despite rapid Chinese port growth and surpassing Hong Kong, due to its logistics hub strategy and the fact that China is still hampered by customs procedures and other political factors that stand in contrast with its enormous potential.

[Figure 3 about here]

\subsubsection{Substructures in the global maritime network}


The search for substructures (also coined communities, clusters, or subgraphs) is one major pillar that had been applied successfully to maritime transport. Numerous algorithms dissect the network into groups of nodes, this time without an arbitrary definition of the "region", but still trying to delineate meaningful elements, where geography, politics, and economics also create barrier effects. Physicists were the first to apply modularity to the global networks of tankers and containerships, confirming a strong influence of spatial proximity on the delineation of clusters, their initial goal being to further understand marine bioinvasions. Chinese geographers were the first to reveal the world's container hubs and their respective "regions" where they dominate; they had many followers. Single linkage analysis applied to the global container shipping network in 1996 and 2006 (Figure 4) confirmed the importance of geographic proximity as most subnetworks were in fact ports in proximity of one local hub. However, one exception to this was the giant "nodal region" centered upon Hong Kong, extending towards both North America and Europe, and including the whole African continent in 2006, mainly driven by the "China effect". Another way to see such changes was to map the entire network and the centrality of port nodes (Figure 5). The major change observed was the growing centrality of Asian ports and the growing bypass of the interoceanic canals to connect Asia with Africa and Latin America more directly, with increasing transversal linkages between the world's two main poles, Asia-Pacific and Euromed-Atlantic.

[Figure 4 about here]

[Figure 5 about here]

With the prime goal to check the multiplex (or multi-layered) structure of the global shipping network, the application of single linkage analysis to five layers of maritime flows (containers, passengers and vehicles, solid bulks, liquid bulks, and general cargo) confirmed that not only more diversified ports are larger and more central more faraway connected than more specialized ports, final results also concluded that shorter linkages are more diversified; mostly container ports dominate their respective nodal region, and the latter regions tend to specialize in one main traffic type (Figure 6). Such invariants largely confirmed stylized facts found in urban studies for instance. Other clustering algorithms helped revealing the other side of the coin: the permanency of "weak links", outside main hubs, for cultural and historical reasons. The Bisecting K-means algorithm applied to the Atlantic network revealed tight but invisible links between the Iberian Peninsula ports and Latin American ports, while the topological decomposition algorithm demonstrated that in the worldwide network, the intercontinental linkages between small and medium-sized ports always contained one or more European ports in addition a port of the former colonial world, showing the traces of past empires. These non-hierarchical subnetworks carry a lot of questions about the volatility of the supposedly economically driven containerization. Links could be made with key notions of resilience, robustness, and proximity in geography and other disciplines.

[Figure 6 about here]

The long-term analysis of the global maritime network (1890-2010) confirmed the shift from a polycentric and dense structure (colonial times) to a bipolar and centralized structure (post1950s), together with a growing simplification or rationalization of the network (Figure 7). One of the main conclusions was that this centralization upon fewer large hubs overtime had not been caused, but reinforced by, containerization, which is often seen as the turning point in 
shipping pattern distribution, although similar competition fostered by technological evolution also occurred in the past such as from sail to steam and combustion, long before the current era of mega-ships. The most striking is that the basic material used for such studies had never been used before, although it had been cited two or three times in the works of ... geographers! The Lloyd's Shipping Index allowed to build a global interport matrix comprising nearly 9,000 ports, 200,000 linkages, and 850,000 vessel movements. The main conclusion was that the global maritime network shifted from efficiency / robustness to centralization / vulnerability.

[Figure 7 about here]

\subsection{Socio-economic and territorial determinants}

The "location" of ports is often given little importance in maritime network studies, as their vast majority only considers the topological space, and the plethora of works about port-city relationships is often theoretical, monographic, without a relational perspective. This section investigates the interplay between maritime transport and two main components of geographic space: a) cities and (subnational) regions; and b) other transport networks of which the road network principally.

\subsubsection{Cities, regions, and maritime flows}

Cities and regions have been the focus of many works on commodity chains, production networks, innovation clusters and so on (Hall and Hesse, 2012), but mostly from the perspective of multinational firms' networks, airlines, etc. Never have cities been confronted in a systematical manner to maritime flows on a global scale and in the long-term. More likely are models and case studies of port-city separation and waterfront redevelopment, transforming former port areas for new urban uses. A minority of works still demonstrate the positive (economic) impact of ports on their belonged territory, especially in emerging economies (cf. BRICS countries), but most scholars ignore the city or see it as a constraint to port development which should be bypassed due to lack of space and congestion. In addition, new ports and transit hubs have barely any effect on their outlying environment. Port-related benefits (value, employment) tend to concentrate in locations without necessarily having a port, like inland or coastal non-port cities.

However, the emergence of large-scale quantitative analyses of port cities and regions in the 2000s allowed detecting important linkages, such as the fact that in Europe, North America, and Japan, larger, richer, denser, and service-oriented cities concentrate the most diversified and valued flows whereas regions handling bulks remain often specialized in the primary sector. Such findings motivated a relational study although most of the time, transport and communication networks were studied without proper urban or regional attributes. The firstever analysis of the world's cities connected by water, based on theories of urban systems, was fruitful in many ways. Mains results (1890-2010) confirmed that the immense majority of world maritime traffic kept concentrating in larger cities, while the latter always exhibited, on average, superior centralities of all kinds, higher rich-club coefficient, higher commodity and ship type diversity, and farther connectivity than smaller cities. Interestingly, the fading linear correlation between urban population and vessel calls observed at port cities per se had, at 
the contrary, constantly increased at extended urban regions, i.e. cities hosting or not ports but being near the coast, thereby confirming the dilution of hinterlands and the changing meaning and nature of the study unit. This study also confirmed that current global cities like London, New York, and Tokyo had been the world's largest maritime hubs in the 1950s, but lost their dominance to more efficient hubs in the following decades (Figure 8), such as Rotterdam and Singapore, which are large cities but not the largest.

[Figure 8 about here]

\subsubsection{The interconnection with other networks}

Although the idea of studying how different (transport) networks combine dates back to the 1960 s in geography, it is only very recently that such a task had been achieved. A growing number of theories and empirical studies of so-called coupled or multiplex networks emerged in natural and social sciences in the late 2000s. Transport studies have increasingly seen maritime transport as one segment only of a wider supply chain comprising other modes, while land transport as a whole often represents about $60 \%$ of the total cost of moving a container from origin to destination. Physicists and geographers first analysed the coupling or "inter-similarity" between global airline and maritime networks. The online GIS ORBIS allows calculating the time and cost of travelling through the sea-land network in Roman antiquity. All other studies of the kind did not include the maritime mode, such as airline / Internet, airline / multinational firms, and airline / road / rail to name but a few.

We present in more detail recent efforts to push further the analysis of sea-road networks. One major obstacle being the absence of data on road (freight) flows, except from certain customs data or commodity flow surveys in developed countries. Such an approach having a global ambition, it relies on maritime flows on the one side and road infrastructure on the other. Raw data from OpenStreetMap was modelled and thus simplified taking into account the quality, rank, and speed limits of street segments to construct a global road network connecting both ports, port cities, and non-port cities inland and along coastlines. Applications were made on Australia and Europe (Figure 9). In both cases, it revealed that combined landsea centrality is always more correlated with urban population than single centrality.

[Figure 9 about here]

One difficulty had been to avoid the island effect (e.g. Tasmania, Malta, Cyprus, Gotland) as the ratio between land-sea centrality and single centrality always produced extreme values in such locations, compared with mainland nodes. More research is needed to push further the understanding of the maritime centrality of inland and non-port cities, especially in Europe, where the concentration of economic wealth, infrastructure and population concentrates along the London-Milano megalopolis, whereas other continents remain dominantly coastal. Another improvement would be to include more transport modes such as river/canal, railway, airlines, and other communication networks to lean towards an all-encompassing global circulation system.

\section{Conclusion}


Despite being a sub-discipline of transport and human geography, the geography of maritime transport is a rich and buoyant research arena. In recent decades, it developed strong links with economics, management, but also geomatics and network analysis. The role of space is increasingly taken into account after a period more focused on actors and strategies, the two being not mutually exclusive. Maritime transport has its specificities in terms of industry but it clearly remains, today, a useful way to understand the world from the local to the global.

\section{Acknowledgements}

The research leading to these results has received funding from the European Research Council under the European Union's Seventh Framework Programme (FP/2007-2013) / ERC Grant Agreement n. [313847] "World Seastems".

\section{Cross-references}

10259 seaports

10386 transportation statistics and databases

10397 transport modes: data, methods and analysis

10476 introduction to maritime transport

10479 the future of maritime transport

10480 maritime transport and territorial scale

10506 port performance

10601 transport modes and big data

10759 data sources for transport modes

\section{Bibliographical references}

Ducruet C. (2015) Maritime Networks. Spatial Structures and Time Dynamics, Routledge Studies in Transport Analysis, Routledge: London \& New York.

Ducruet C. (2017) Advances in Shipping Data Analysis and Modeling. Tracking and Mapping Maritime Flows in the Age of Big Data. Routledge Studies in Transport Analysis, Routledge: London \& New York.

Hall P.V., Hesse M. (2012) Cities, Regions and Flows. London \& New York: Routledge.

Lewis M.W., Wigen K. (1999) A maritime response to the crisis in area studies. The Geographical Review, 89(2): 161-168.

Ng A.K.Y., Ducruet C., Jacobs W., Monios J., Notteboom T.E., Rodrigue J.P., Slack B., Tam K.C., Wilmsmeier G. (2014) Port geography at the crossroads with human geography: between flows and spaces. Journal of Transport Geography, 41: 84-96. 
Robinson R. (1968) Spatial Structuring of Port-Linked Flows: The Port of Vancouver, Canada, 1965. Thèse de Géographie, Université de Colombie Britannique.

\section{Further reading}

Berli J., Bunel, M., Ducruet C. (2019) Sea-land interdependence in the global maritime network: the case of Australian port cities. Networks and Spatial Economics, 18(3): 467-471.

Birtchnell T., Savitzky S., Urry J. (2015) Cargomobilities. Moving Materials in a Global Age, Routledge: London \& New York.

Frémont A. (2007) Global maritime networks: The case of Maersk. Journal of Transport Geography, 15(6): 431-442.

Jacobs W., Koster H.R.A., Hall P.V. (2011) The location and global network structure of maritime advanced producer services. Urban Studies, 48(13): 2749-2769.

Leymarie P., Rekacewicz P., Stienne A. (2014) UNOSAT Global Report on Maritime Piracy. A Geospatial Analysis 1995-2013. United Nations Institute for Training and Research (UNITAR).

Rodrigue J.P., Notteboom T.E., Shaw J. (2013), The SAGE Handbook of Transport Studies, SAGE Publications.

Rodrigue J.P., Comtois C., Slack B. (2013) The Geography of Transport Systems. New York: Routledge. Schwanen T. (2017) Geographies of transport II: Reconciling the general and the particular. Progress in Human Geography, 41(3): 355-364.

Shaw J., Sidaway J.D. (2011) Making links: On (re)engaging with transport and transport geography. Progress in Human Geography, 35(4): 502-520. 


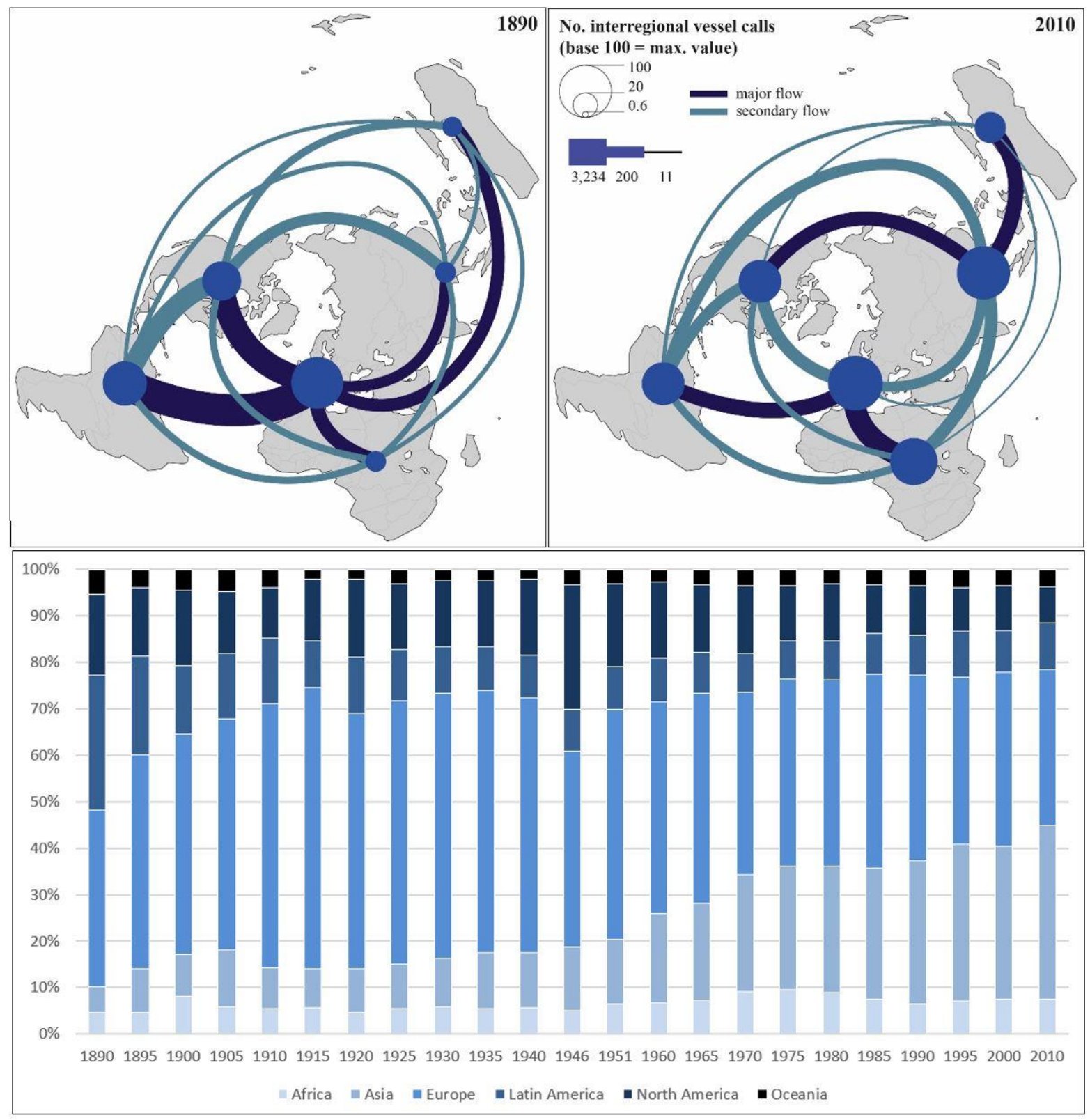

Figure 1 World distribution of vessels calls in 1890 and 2010. 

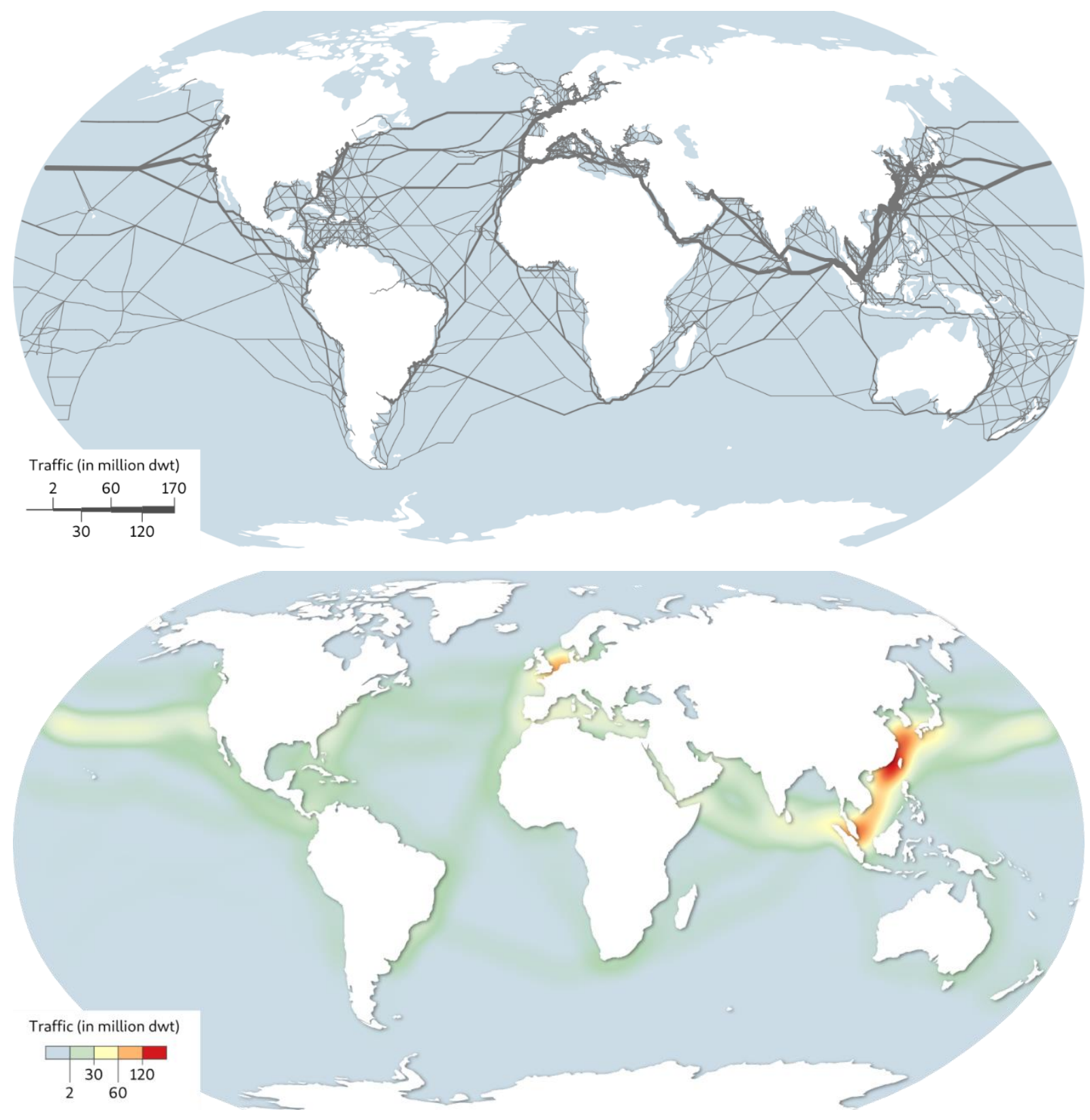

Figure 2 Global pattern of maritime container shipping routes 


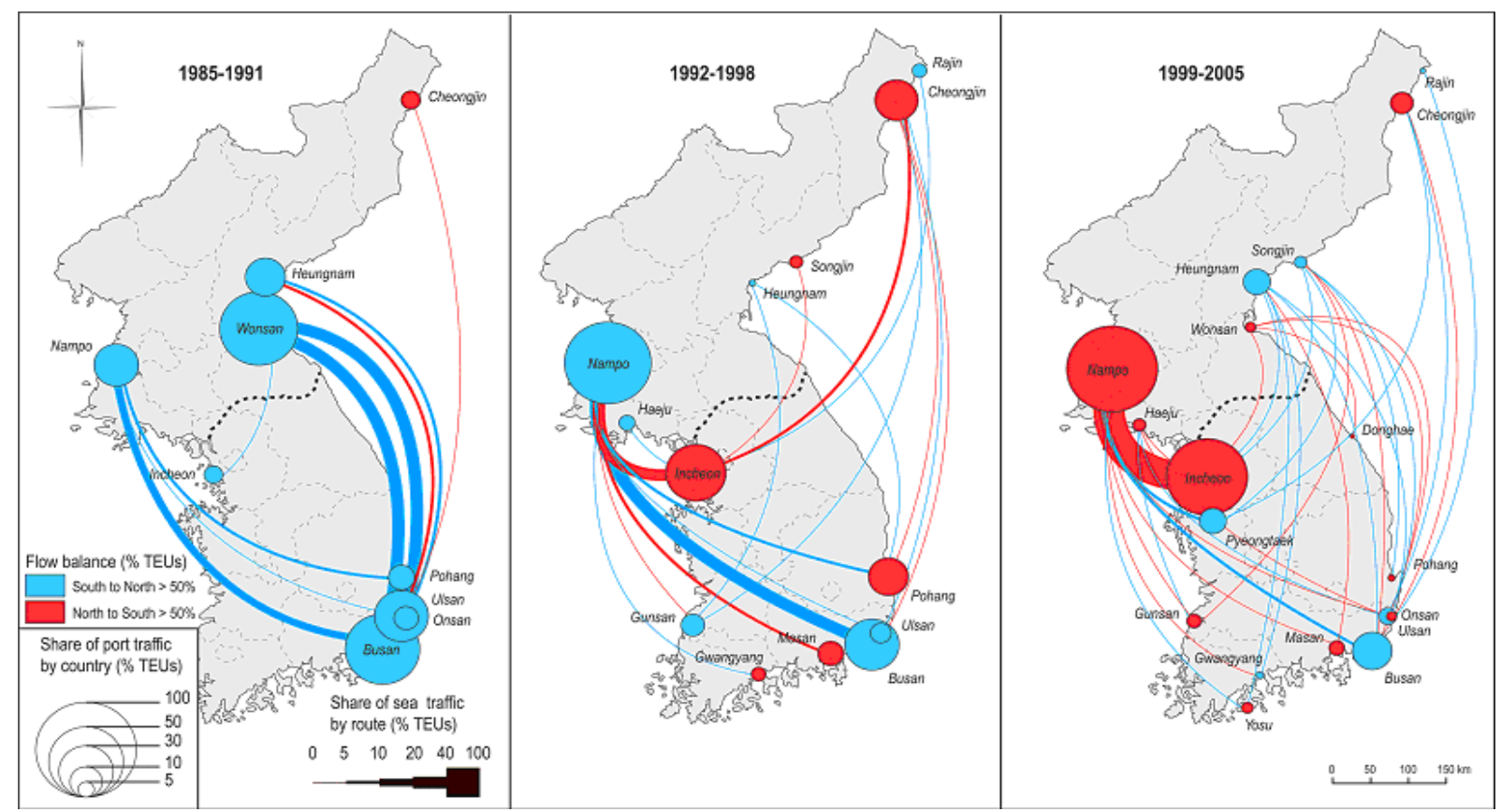

Figure 3 Inter-Korean maritime flows, 1985-2005

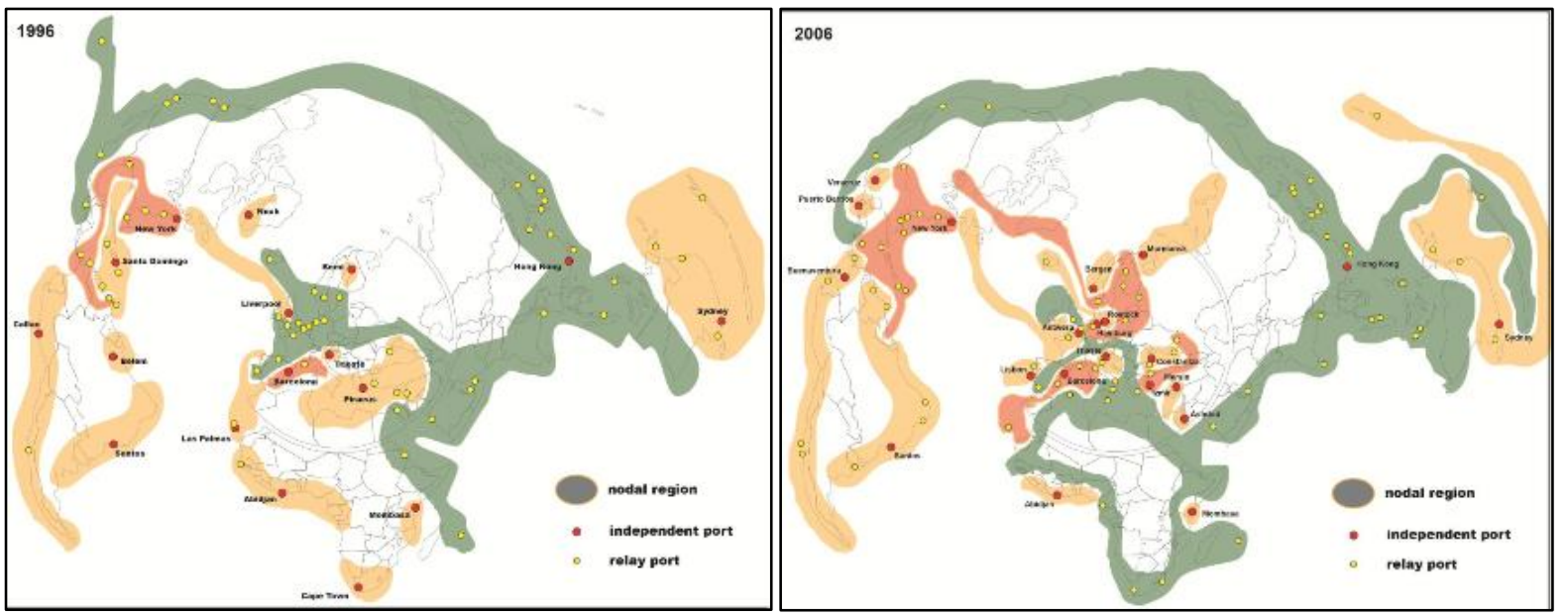

Figure 4 Nodal regions in the global container shipping network in 1996 and 2006 


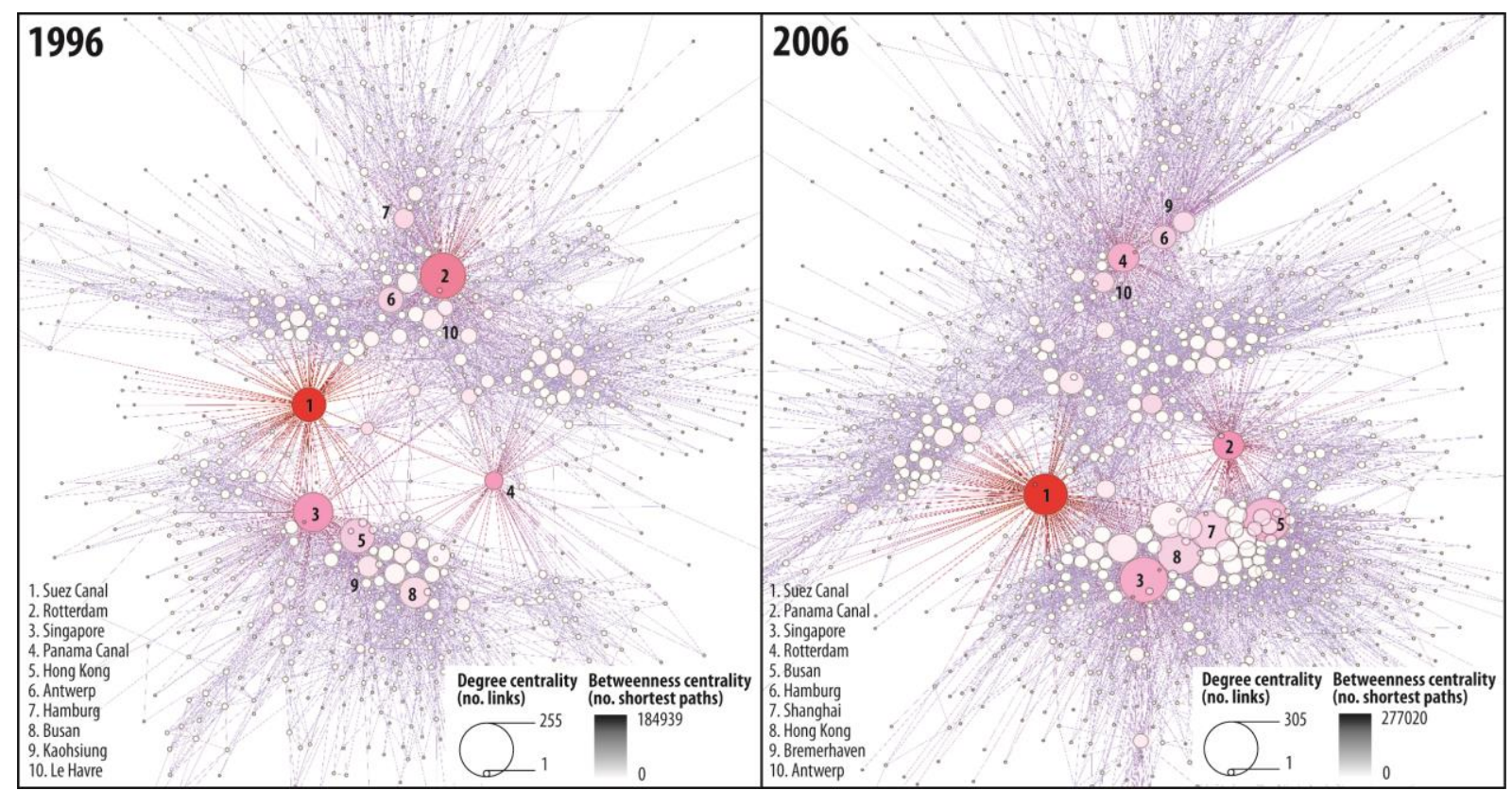

Figure 5 Graph visualization of canal and port centrality in 1996 and 2006

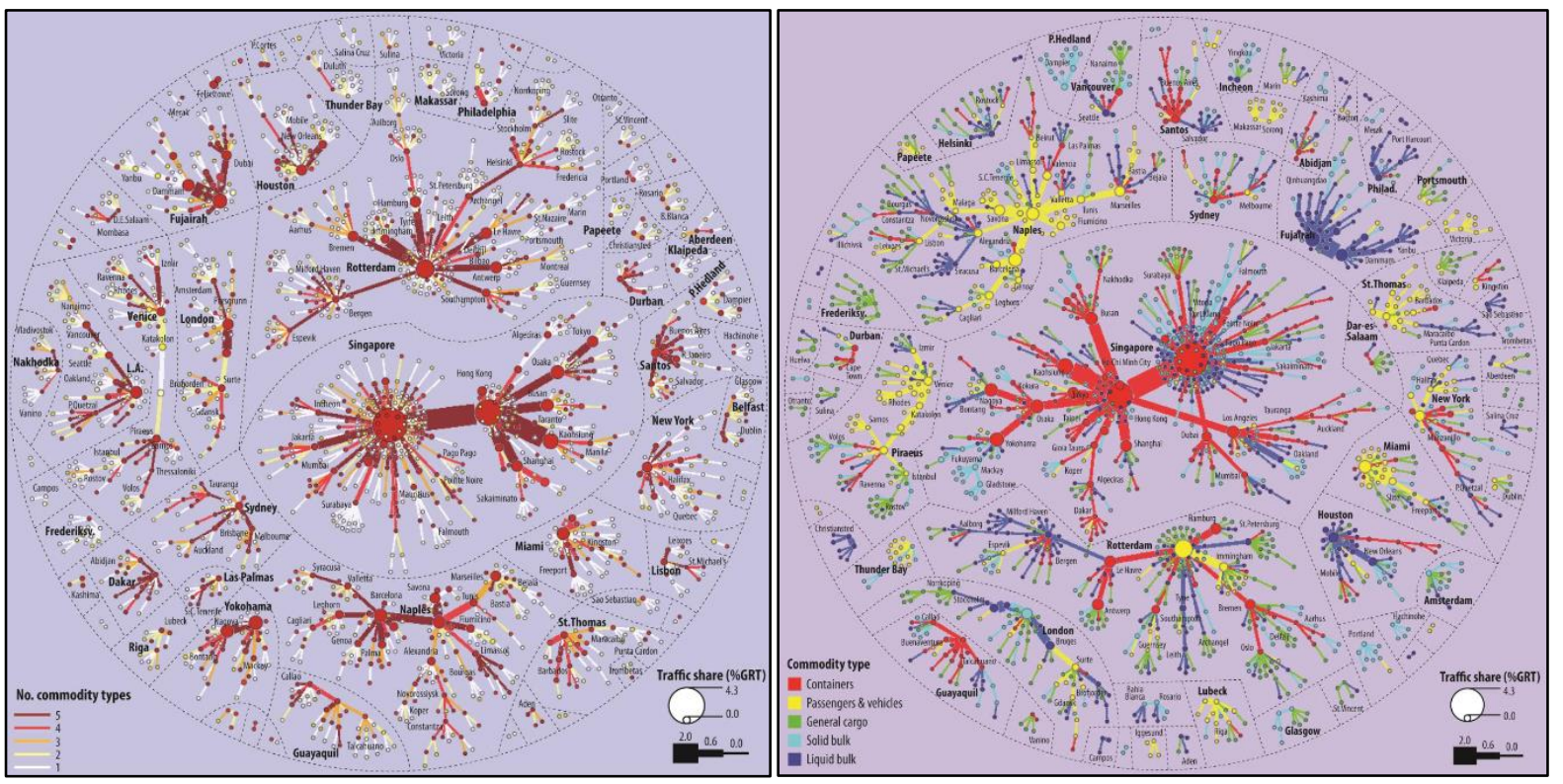

Figure 6 Network diversity and centralization of global maritime flows in 2004 


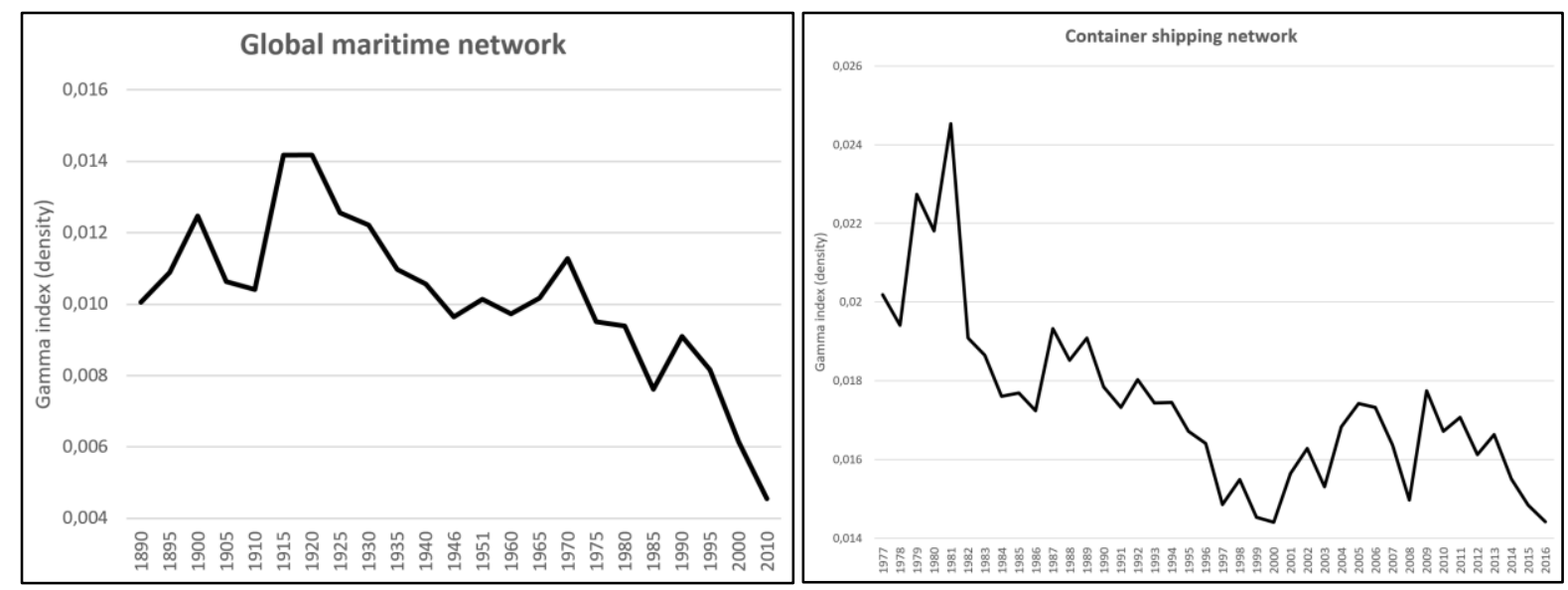

Figure 7 Density evolution of the global maritime network, all vessels (A) and containerships (B)

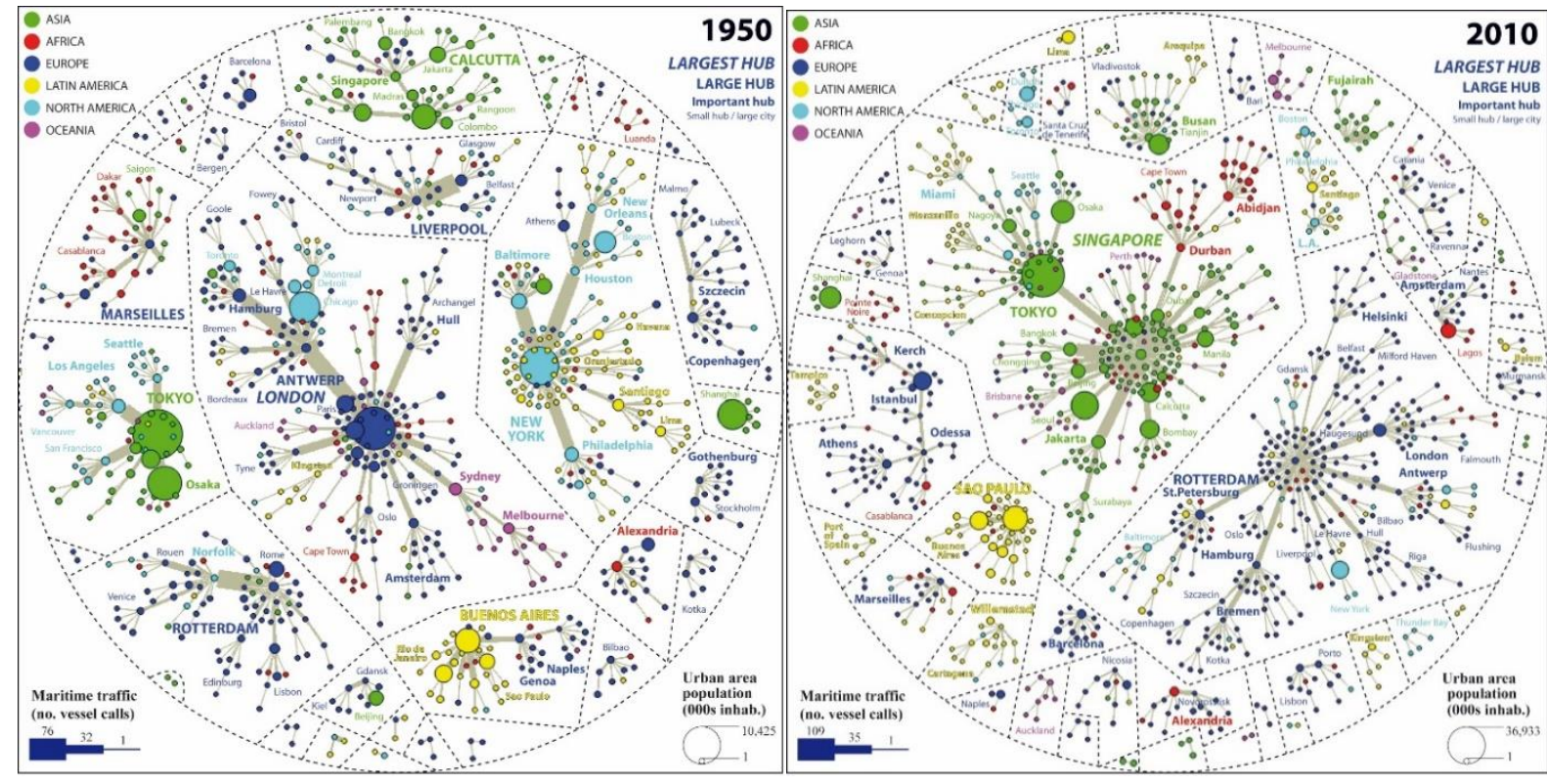

Figure 8 Urban centralization of the global maritime network in 1950 and 2010 


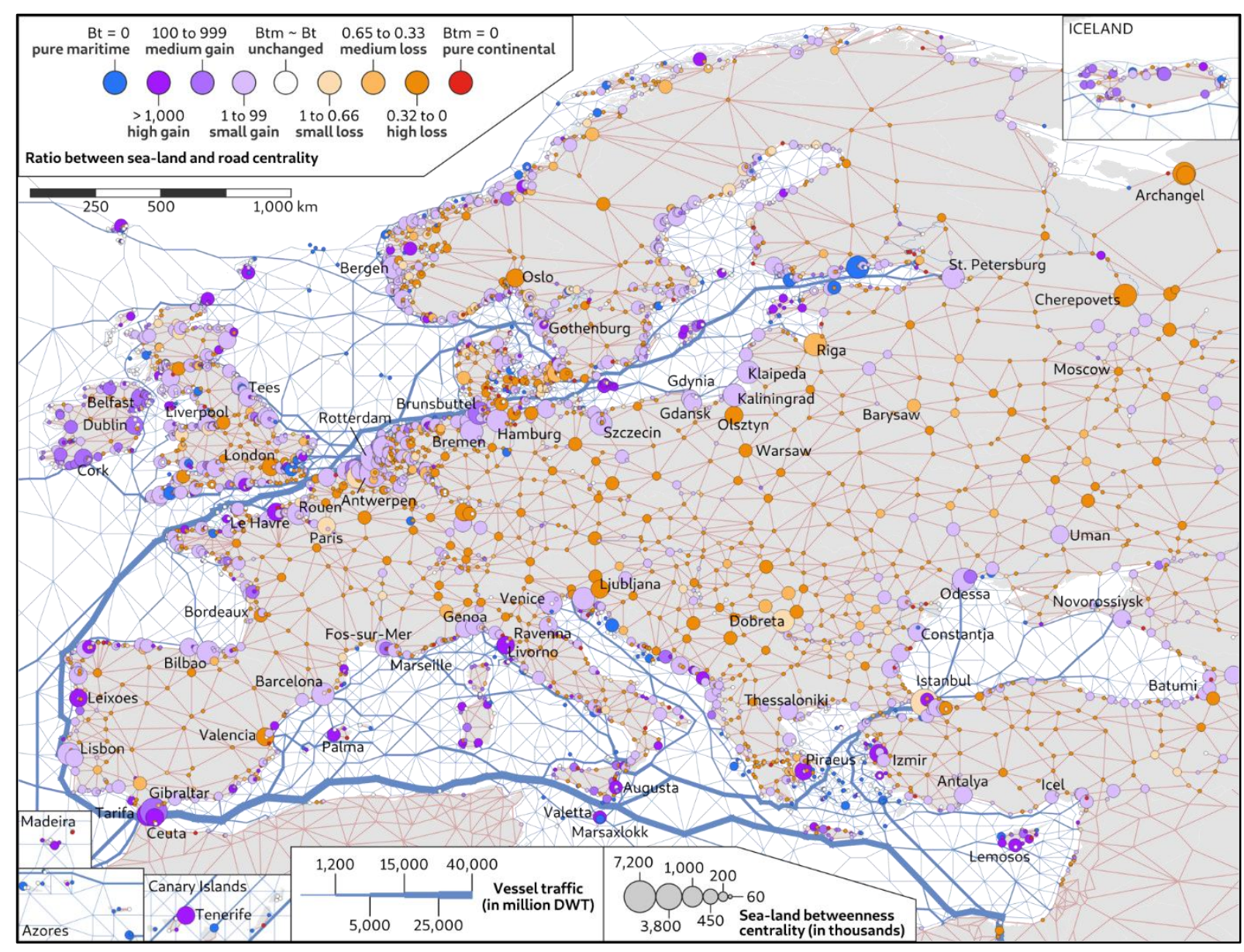

Figure 9 Sea-land connectivity of European ports and cities in 2008 